\title{
LA IGUALDAD DE GÉNERO EN LA LEGISLATURA CONSTITUYENTE: NOTAS SOBRE LA ELABORACIÓN DE LA CONSTITUCIÓN ESPAÑOLA DE 1978 RESPECTO DE LAS CUESTIONES RELACIONADAS CON LA SITUACIÓN DE LAS MUJERES ${ }^{1}$
}

\author{
Mar Esquembre \\ mm.esquembre@ua.es \\ Universidad de Alicante
}

Recibido: 28-02-2013

Aceptado: 21-03-2013

\begin{abstract}
Resumen
El presente trabajo se centra en señalar cuál fue la posición que las principales cuestiones relacionadas con la situación de las mujeres ocuparon en el proceso de elaboración en sede parlamentaria de la Constitución española de 1978. Para ello se analiza pormenorizadamente, utilizando como fuente básica las publicaciones oficiales del Congreso y del Senado, el debate constituyente en ambas Cámaras, en especial el relativo a los artículos más relevantes en relación con la situación de las mujeres y que enlazaban de forma más directa con las reivindicaciones del movimiento feminista respecto del texto constitucional: igualdad, matrimonio y familia. Como se desprende del análisis, el mítico consenso constitucional se construyó sobre la base de no reconocer constitucionalmente reivindicaciones feministas tales como el divorcio o el aborto, posponiéndolas a un desarrollo normativo posterior.
\end{abstract}

Palabras Clave: Igualdad, mujeres, legislatura constituyente, debate constitucional, transición española

\begin{abstract}
The present work is based on indicating which was the place occupied by the principal issues related to the situation of the women in the process of production in the Spanish Constitutional parliament of 1978. To accomplish that, it is analysed deeply, using as basic source the Congress and Senate official publications, the constitutional debate in both houses, especially related to the most relevant articles in relation with the situation of women, more directly connected to the feminist movement demands in the constitutional text: equality, marriage and family. According to the analysis, the mythical constitutional consensus was built based on no constitutional recognition of feminist demands such as divorce or abortion, postponing them to a later development into rules.
\end{abstract}

Keywords: Equality, women, constituent legislature, constitutional discussion, Spanish transition.

\footnotetext{
${ }^{1}$ Este estudio ha sido realizado en el marco del Proyecto de investigación "Haciendo Historia: Género y Transición en España”, financiado por el MICINN (Ref. FEM2010-19068).
} 


\section{Introducción}

El objetivo del presente trabajo se centra en señalar cuál fue la posición que las principales cuestiones relacionadas con la situación de las mujeres ocuparon en el proceso de elaboración en sede parlamentaria de la Constitución española de 1978. Para ello se analiza pormenorizadamente, utilizando como fuente básica las publicaciones oficiales del Congreso y del Senado, el debate constituyente en ambas Cámaras, en especial el relativo a los artículos más relevantes en relación con la situación de las mujeres y que enlazaban de forma más directa con las reivindicaciones del movimiento feminista respecto del texto constitucional: igualdad, matrimonio y familia.

No se aborda en este trabajo el derecho a la educación, lo que no supone que se le reste importancia. Dos son las razones para no incluirlo aquí. De un lado, porque en el presente volumen ya se incluye un trabajo específico al respecto. De otro, porque no reviste, de forma directa, especial interés por lo que se refiere a la igualdad de mujeres y hombres en lo que atañe al intensísimo debate parlamentario sobre el mismo ${ }^{2}$.

Tampoco se analiza el interesante debate sobre la discriminación por razón de sexo constitucionalizada en el orden sucesorio de la Corona por limitaciones de espacio y, principalmente, por no ser ésta cuestión que afectase de forma directa a la situación de las mujeres en general $^{3}$.

A efectos de una mejor sistematización y clarificación, en este trabajo hemos optado por analizar en epígrafes distintos el debate en el Congreso y el desarrollado en el Senado. Como ya es sabido, la redacción del texto definitivo de la Constitución hubo de encomendarse a una Comisión mixta Congreso-Senado ${ }^{4}$. Reunida en sesiones secretas para estudiar las discrepancias entre los textos aprobados por el Congreso y por el Senado, elaboró un texto consensuado que se aprobó definitivamente por los Plenos del Congreso y del Senado ${ }^{5}$. No le dedicamos, por tanto, ningún apartado específico pues debido a ese carácter secreto de los trabajos no hay constancia de los debates que se hubieran podido suscitar. Sí hay que señalar que en los tres temas que aquí se analizan hubo de consensuarse un texto que sincretizaba los

\footnotetext{
${ }^{2}$ Basta, en este sentido, hacer sólo una referencia a la enmienda $\mathrm{n}^{\circ} 696$, presentada por la diputada comunista Pilar Brabo, por ser el único aspecto novedoso y más relevante a los efectos que nos interesan aquí, pues fue la única ocasión en que se planteó la posibilidad de introducir en la Constitución el principio de la coeducación. Con el rechazo inicial por la Ponencia de esta enmienda que proponía añadir un apartado en el que se estableciese que "en todo caso los centros públicos se organizarán en régimen de coeducación" (Cortes Generales, 1980: 423), se perdió la ocasión de dar rango constitucional a la exigencia de la coeducación en la enseñanza, al menos, de los centros oficiales. En la actualidad la coeducación, por desgracia, ni siquiera tiene rango legal.

${ }^{3}$ Aunque resulta muy interesante que éste fuese el motivo que propició una alianza entre las 21 diputadas de aquella legislatura constituyente, independientemente de su adscripción a partidos políticos de diferente ideología (Sevilla et al., 2006: 131).

${ }^{4}$ Esta Comisión, de la que no formaba parte ninguna de las 27 parlamentarias (21 diputadas y 6 senadoras), comenzó sus trabajos el 16 de octubre de 1978 y el texto consensuado se publicó en el Boletín Oficial de las Cortes, $\mathrm{n}^{\circ} 170$, de 28 de octubre de 1978.

${ }^{5}$ La aprobación tuvo lugar en cada una de las Cámaras el 31 de octubre de 1978.
} 
aprobados por las Cámaras, tal y como puede comprobarse al confrontar los mismos (que figuran en este trabajo) con el texto de los artículos 9.2, 14, 32 y 39 de la Constitución española.

\section{La igualdad de género en el debate de la Constitución en el Congreso}

A pesar de la efervescencia del movimiento de mujeres y feminista y de que todos los partidos políticos introdujeron en sus programas políticos el tema de "la mujer", las referencias a sus reivindicaciones apenas tuvieron eco en las primeras intervenciones de carácter general en la Cámara el mismo día de su constitución ${ }^{6}$ (Sevilla et al., 2006: 9-23 y 35-42). Como veremos, "son los silencios, en vez de los discursos, lo que más revelan sobre el lugar del género en la Constitución" (Radcliff, 2012: 208).

Así, el portavoz del GP Socialista, Felipe González, afirma que "deben incluirse los derechos de la mujer" (Congreso de los Diputados, 1977: 69) cuando se refiere a la elaboración de la Constitución como tarea inmediata de las recién constituidas Cortes. En parecidos términos se pronunció el diputado Raventós Carner, en representación del GP Socialista de Cataluña, al comparar metonímicamente la Constitución al "Estatuto de las libertades fundamentales de los ciudadanos, con la mayoría de edad a los dieciocho años, y la absoluta igualdad entre el hombre y la mujer" (Congreso de los Diputados, 1977: 98).

El portavoz del GP Comunista, Santiago Carrillo, es algo más explícito, pues al referirse también al contenido de la futura elaboración de la norma básica, afirma que ha de ser una Constitución que "garantice la igualdad jurídica entre la mujer y el hombre, reparando injusticias históricas escandalosas" (Congreso de los Diputados, 1977: 73). Se aprecia, no obstante, una mayor sensibilidad cuando, avanzando en su discurso, habla de la amnistía, pues se refiere a la misma en sentido amplio y no limitándose únicamente a los delitos de intencionalidad política, sino que "También debe aplicarse la amnistía a delitos establecidos en el Código Penal para la mujer, con evidente discriminación, y que han dejado de serlo en la mayoría de los países civilizados" (Congreso de los Diputados, 1977: 73). No es sorprendente esta inclusión en su discurso, habida cuenta que, a instancias de la diputada feminista de este grupo parlamentario, $\mathrm{M}^{\mathrm{a}}$ Dolores Calvet, se había presentado una moción en este sentido. No hay que olvidar tampoco al respecto la influencia que necesariamente tuvo el Movimiento Democrático de Mujeres, pues no en vano había surgido propiciado por el Partido Comunista en la clandestinidad.

La situación de desigualdad de las mujeres no podía obviarse ni siquiera por las formaciones políticas más conservadoras, como lo demuestra la intervención del portavoz del GP de Alianza Popular, Manuel Fraga, que afirma, ya acabando su discurso, que:

\footnotetext{
${ }^{6}$ Diario de Sesiones del Congreso de los Diputados, no 5, de 27 de julio de 1977.
} 
“Tenemos una gran oportunidad [...] de aumentar cada día el nivel de participación de todos los ciudadanos y de todos los grupos y, en particular, de la juventud española y de la mujer, que aún esperan el pleno reconocimiento de igualdad" (Congreso de los Diputados, 1977: 96).

En esta misma sesión se dio lectura a las diferentes propuestas y mociones presentadas a la Cámara. Entre las diferentes propuestas y mociones cabe destacar la Proposición de ley sobre amnistía referida a los delitos de adulterio, aborto y propaganda y difusión de anticonceptivos (presentada por el GP comunista) y la Moción para la despenalización del adulterio (presentada por el GP mixto).

Cinco días después de estas intervenciones, el 1 de agosto de 1977, se constituye la Comisión que se encargaría de iniciar los trabajos de la Constitución y de elaborar el proyecto que se debatiría en el Pleno. Sólo una diputada, Teresa Revilla López, forma parte de la Comisión Constitucional por expresa petición propia (Sevilla et al., 2006: 90) junto a otros treinta y ocho diputados. La Ponencia elegida para redactar el Anteproyecto de la Constitución estaba compuesta por siete diputados (Congreso de los Diputados, 1977: 105) que, muy pronto, fueron denominados los "padres de la Constitución".

El informe de la Ponencia (Congreso de los Diputados, 1978a), cuyos trabajos tuvieron carácter "reservado" (y es bien conocido que las principales negociaciones tuvieron lugar fuera de la sede parlamentaria) fue sometido a debate en la ya por entonces denominada Comisión de Asuntos Constitucionales y Libertades Públicas del Congreso durante mayo y junio de 1978. El debate en el Pleno del Congreso sobre el Dictamen de la Comisión tuvo lugar en doce sesiones desde el 4 al 21 de julio de 1978. Su resultado se plasmó en la elaboración de un texto de Proyecto de Constitución, que fue sometido a votación en su conjunto, en la sesión de 21 de julio de 1978 (Congreso de los Diputados, 1978j), remitiéndose al Senado para su tramitación.

\subsection{Las cuestiones más relevantes en relación a la posición de las mujeres}

Las que serán las cuestiones más relevantes para las mujeres son ya aludidas en el debate general en la Comisión a la totalidad del anteproyecto elaborado por la Ponencia, como se desprende de las intervenciones de los representantes de los grupos parlamentarios Comunista y de Alianza Popular y de formaciones políticas minoritarias como Unió de Centre y la Democracia Cristiana de Cataluña o Euskadiko Ezquerra.

En una postura favorable a la constitucionalización de materias relevantes en orden a la consecución de la igualdad de mujeres y hombres se sitúan en este debate el GP Comunista y Euskadiko Ezquerra. En la postura contraria, el GP de AP y la Democracia Cristiana de Cataluña, que abogan por una conservación del orden patriarcal mediante el refuerzo de la posición de la familia y la defensa de los papeles tradicionales asignados a hombres y mujeres en el seno de la misma. 
En representación del GP Comunista interviene Santiago Carrillo, que, tras advertir que el proyecto que se discute es de tendencia conservadora, dado el contexto político-social, anuncia la presentación de enmiendas porque "pensamos que temas como el divorcio, la abolición de la pena de muerte y el aborto deberían quedar resueltos en la Constitución" (Congreso de los Diputados, 1978b: 2040). A pesar de ser escasas líneas en un discurso de cinco páginas, es la alusión más clara y directa que se hace en el debate general a las materias que aquí consideramos de especial interés.

La única intervención que hace referencia a los derechos de las mujeres es la del portavoz de Euskadiko-Ezkerra, Francisco Letamendía, que, al referirse a los apoyos que merezcan las enmiendas presentadas por otros grupos, resalta especialmente que "Defenderemos a vuestro lado [...] una expresión clara de los derechos de las mujeres, que deben concretarse en la mención expresa del divorcio en el artículo 31, y de los derechos a la planificación familiar y a la interrupción del embarazo, en el artículo 35" (Congreso de los Diputados, 1978c: 2085).

En representación del GP de AP, interviene Manuel Fraga, que destaca, como uno de los grandes compromisos de la Constitución, como una de las cuestiones en las que es necesario llegar a grandes acuerdos de base, las cuestiones religiosas y morales. Y señala que a este respecto la Constitución aborda cuatro puntos básicos, entre los que podemos destacar "los principios básicos en materia de educación" y “el régimen de la institución familiar" (Congreso de los Diputados, 1978b: 2043), donde se incluye tanto el precepto relativo al matrimonio como el referido a la familia. También incluye el representante de AP una referencia a la igualdad, pero no para referirse a la igualdad de género, sino, en sus palabras, "en la creación de un mínimo nacional para todos los españoles" (Congreso de los Diputados, 1978b: 2045).

Por la Unió de Centre y la Democracia Cristiana de Cataluña interviene Antón Canyellas, que sí hace referencia directa a temas como la familia y el divorcio, así como al aborto, lógicamente de carácter conservador, en consonancia con la ideología defendida por la formación política a la que pertenece. Así, al referirse a los derechos y libertades incluidos en el texto constitucional afirma que:

"Falta, a nuestro modo de ver, una declaración contundente, al igual que lo hace el Pacto Internacional de Derechos Civiles y Políticos, de afirmación de que la familia es el elemento natural y fundamental de la sociedad y tiene derecho a la protección de la sociedad y del Estado" (Congreso de los Diputados, 1978c: 2072).

Con respecto al aborto, lo unen a la redacción del precepto que consagra el derecho a la vida, para incluir entre los titulares de este derecho al nasciturus, oponiéndose totalmente al aborto excepto cuando se trate de "poderosas razones terapéuticas y en los casos trágicos de una única alternativa de elección entre la vida del feto y de la madre" (Congreso de los Diputados, 1978c: 2073).

Sentadas así las posiciones progresistas y conservadoras en las que se alinearían según su ideología las restantes fuerzas políticas, comenzó propiamente el debate, pues hasta ese 
momento, fue exclusivamente la Ponencia constitucional la encargada de ordenar todas las enmiendas y votos particulares presentados, admitiendo unos y rechazando otros, pero sin más debate o discusión que la que se pudiera producir, sin luz ni taquígrafos, entre los siete "padres de la Constitución".

\section{a) El debate sobre la igualdad: artículos 9.2 y 14}

En el Anteproyecto de Constitución redactado inicialmente por la Ponencia se recogen tanto la denominada igualdad real o material (art. 9.2) ${ }^{7}$ como la igualdad formal (art. 14) ${ }^{8}$. Ninguno de los dos artículos fue objeto de votos particulares por los Grupos parlamentarios. Se presentaron siete enmiendas al art. 9.2 (una del GP Mixto, otra por GP de UCD y las cinco restantes por diputados de AP, UCD y GP Comunista), cuyo contenido oscilaba entre las peticiones de supresión por entender que su contenido ya estaba presente en los valores superiores del art. 1 (AP) hasta su corrección gramatical o una nueva redacción que incidiese en el cambio de las estructuras socioeconómicas (GP Mixto). El art. 14 fue objeto de cinco enmiendas (una por el GP Socialista, otra por GP Mixto y las tres restantes por diputados de AP, UCD y GP Comunista), que pretendían añadir más causas a la prohibición de discriminación (fortuna o razones económicas, la lengua) o bien restringirlas mediante la supresión de la última parte del precepto (AP), planteándose también un traslado del artículo al Título I, concretamente al art. 3 (GP Comunista). Resulta, por esta razón, curioso, que, figurando el sexo como primera causa de no discriminación en la redacción original, sea desplazada al tercer lugar, después del nacimiento y la raza, en el texto que la ponencia presenta para su debate en Comisión.

El artículo 9 es debatido en la sesión de la Comisión de Asuntos Constitucionales y Libertades Públicas de 16 de mayo (Congreso de los Diputados, 1978d: 2380-2390), si bien los apartados más polémicos son el primero y el tercero, pues el apartado 2 fue objeto de sólo dos enmiendas que fueron retiradas. No hubo, pues, propiamente, debate, quedando este apartado redactado en los términos ya fijados por la Ponencia.

Por lo que se refiere a la igualdad jurídica o formal, se retiran las tres únicas enmiendas presentadas por los GP Socialista, de AP y el Mixto. Por tanto, se vota el texto de la Ponencia, que es aprobado por unanimidad.

En ese momento hace uso de la palabra la diputada Teresa Revilla, para explicar el voto a este artículo en la única intervención en todo el debate constitucional en que se pone de

\footnotetext{
${ }^{7}$ El texto era el siguiente: "Corresponde a los poderes públicos promover las condiciones para que la libertad y la igualdad del individuo y de los grupos en que éste desarrolla su personalidad sea real y efectiva; remover los obstáculos que impidan o dificulten su plenitud, y facilitar la efectiva participación de todos los ciudadanos en la vida política, económica, cultural y social del país" (Congreso de los Diputados, 1978: 671).

${ }^{8}$ El texto era el siguiente: "Los españoles son iguales ante la ley sin discriminaciones por razón de sexo, de raza, de nacimiento, de religión, de opinión o de cual esquiera otras condiciones personales o sociales" (Congreso de los Diputados, 1978: 671).
} 
relieve la situación de histórica marginación de las mujeres hasta ese momento, de un lado, y, de otro, la constatación de que el reconocimiento de la igualdad formal es simplemente el inicio del largo camino por recorrer para la consecución real de la igualdad de mujeres y hombres, cuestión que no sólo atañe a las mujeres, sino a la sociedad en su conjunto. Por su interés, reproducimos íntegramente la intervención de la diputada Revilla:

"Señorías, en este artículo que hemos votado afirmativamente, la mujer española adquiere, por fin, la plenitud de derechos. Es verdad que la votación ha sido unánime, sin disidencias, como estaba reclamando nuestra sociedad. Pero las mujeres no vamos a dar las gracias por ello. Tampoco vamos a mirar hacia el pasado con amargura o con rencor. Ahora buscamos el futuro y en el futuro queremos simplemente poder ser, para ser lo que podamos. Queremos conservar nuestra feminidad, que es un atributo precioso de la humanidad y, al mismo tiempo, sin renunciar a poder ser protagonistas de nuestra propia vida y a participar en igualdad de esfuerzos y responsabilidades en el quehacer común.

Para ello necesitamos, además de la igualdad ante la ley, de una sociedad rica en posibilidades de vida y en formas de existencia, una sociedad flexible en sus sistemas de trabajo y de educación, donde no sean incompatibles la maternidad y el trabajo, la vida familiar y la cultura. La mujer necesita de una sociedad flexible y plural, pero también la necesita el hombre, que empieza hoy a sentirse atrapado en un destino unidimensional.

Y para terminar, Señorías, que no se piense que la crisis de identidad de la mujer es sólo un problema femenino, de mujeres, porque es un problema de la sociedad en su conjunto. La sociedad lo sufre y la sociedad se enriquecerá en sus soluciones" (Congreso de los Diputados, 1978e: 2445-2446).

Al no haberse presentado enmiendas, en el debate en Pleno el texto de ambos artículos permanecerá inalterado. Y ni siquiera fueron objeto de una explicación del voto. Sólo al inicio del citado debate, en la exposición sobre el conjunto del proyecto, antes de iniciarse el debate al articulado, se hace referencia a la igualdad por parte del representante del GP Comunista. Santiago Carrillo, afirmaba entonces que la igualdad real entre mujeres y hombres constituye un elemento de sentido programático expresado en nuestra Constitución que requeriría, por tanto, de la acción por parte de los poderes públicos a fin de dar un contenido real a estas aspiraciones, si bien matizó que ello no sería posible hasta que la clase obrera lograse ocupar un espacio amplio de poder (Congreso de los Diputados, 1978g: 3782-3783).

Ni el art.1.1 ni el art. 9.2 ni el actual art. 14 fueron objeto, pues, de debate en el Pleno del Congreso.

\section{b) Matrimonio: artículo 32}

$\mathrm{Al}$ art. 27 del primer Anteproyecto, relativo al matrimonio ${ }^{9}$, presentaron votos particulares el GP Comunista y el GP Socialista a fin de clarificar la opción del divorcio o de

\footnotetext{
${ }^{9}$ El texto, dividido en dos apartados, era el siguiente: "1. A partir de la edad núbil, el hombre y la mujer tienen el derecho a contraer matrimonio y a crear y mantener, en igualdad de derechos, relaciones estables de familia. 2. El derecho civil regulará las formas del matrimonio, los derechos y deberes de los
} 
constitucionalizar otras formas de familia que no se basaran en el matrimonio como elemento fundante.

Mientras la alternativa planteada por el GP Comunista se limitaba a basar el matrimonio "en la plena igualdad de derechos y deberes de ambos cónyuges" y a la posibilidad de su disolución "por mutuo disenso o a petición de cualquiera de los cónyuges, con alegación en este caso de justa causa", el voto particular del GP Socialista iba mucho más allá, puesto que proponía la sustitución del texto del art. 27 por otro del siguiente tenor:

"1. Toda persona tiene derecho al desarrollo de su afectividad y su sexualidad: a contraer matrimonio, a crear en libertad, relaciones estables de familia y a decidir, libremente, los hijos que desea tener, a cuyo fin tiene derecho a acceder a la información necesaria y a los medios que permitan su ejercicio.

2. Los padres deben prestar a sus hijos alimentos, educación, instrucción y toda asistencia durante la minoría. El Estado vela por el cumplimiento de estos deberes y, en su caso, los satisface subsidiariamente. Se autoriza la investigación de la paternidad.

3. La adopción se producirá bajo la intervención y vigilancia del Estado.

4. El matrimonio puede disolverse por mutuo disenso y a petición de cualquiera de los cónyuges, si concurre justa causa en la forma que se establezca por ley de divorcio" (Congreso de los Diputados, 1978: 714).

En este voto particular, en coherencia con su planteamiento de renunciar al matrimonio como único cauce de establecimiento de una familia, el GP socialista plantea temas, como la asistencia a los hijos por parte de los padres, que serán objeto de otro artículo, el 34, dedicado a la familia, como veremos más adelante. De otro lado, la posibilidad de investigación de la paternidad o la referencia a la adopción son cuestiones únicamente planteadas por este Grupo parlamentario, si bien ya fueron contempladas en la Constitución republicana de 1931, en lo que suponía una de las posturas más avanzadas de la época en el Derecho Constitucional comparado. Es destacable asimismo la relación que se establece entre el derecho al desarrollo de la afectividad y la sexualidad y el derecho a crear relaciones estables de familia.

Por lo que se refiere a las enmiendas planteadas, cabe destacar, por su carácter progresista, las planteadas por el diputado de Euskadiko Eskerra ( $\mathrm{n}^{\circ}$ 64) y por Raúl Morodo, del Grupo Mixto ( $n^{\circ} 479$ ), de adhesión al voto particular del GP socialista y al GP Comunista; por el GP de la Minoría Catalana ( $\left.n^{\circ} 125\right)$, en la que no sólo se hace mención específica de la palabra "divorcio" (es el único texto, junto a otras dos enmiendas, una del GP Vasco -n 607- y otra del GP Comunista - $n^{\circ}$ 697-, en el que se plantea este término directa y explícitamente), sino que se hace referencia a aspectos tan polémicos en la época como el divorcio o el aborto o la propuesta de programas de planificación familiar en consonancia con el debate legislativo iniciado en esa legislatura sobre la despenalización de la venta y publicidad de los anticonceptivos (Sevilla et al., 2006: 195 y 206-226).

cónyuges, las causas de separación y disolución, y sus efectos" (Congreso de los Diputados, 1978: 673674). 
Finalmente, el GP Comunista plantea en una enmienda $\left(n^{\circ}\right.$ 697) un retoque a la redacción propuesta en su voto particular para introducir la patria potestad compartida en condiciones de igualdad, es decir, "sin que proceda establecer un rango prioritario de titularidad de la patria potestad" (Cortes Generales, 1980: 425) como se afirma en la motivación de la enmienda ${ }^{10}$. En el mismo sentido también plantea enmienda el diputado Carlos Güel de Sentmenat (GP mixto) (coalición elactoral Unió del Centre i la Demacràcia Cristiana de Catalunya).

De orientación contrapuesta, las enmiendas planteadas por el GP de UCD ( $\left.n^{\circ} 779\right)$, o por diputados pertenecientes al mismo $\left(n^{\circ} 736, n^{\circ} 756\right)$ proponen una redacción que evite la admisión de cualquier forma de familia estable alternativa a la matrimonial, enfatizando, a la vez, la concepción de la familia como "célula natural y fundamental de la sociedad" basada sobre el matrimonio (Cortes Generales, 1980: 472).

Las enmiendas restantes, todas planteadas por diputados de AP, comparten los mismos principios inspiradores que las de UCD, si bien van más allá al plantear la supresión del apartado segundo por considerar que no es ésta materia que haya de regularse en la Constitución ( $\left.n^{\circ} 2, n^{\circ} 63, n^{\circ} 691\right)$ o, incluso, llegan a proponer que al texto del apartado 2 del art. 27 se añada que "En todo caso el reconocimiento del divorcio requerirá el referéndum público de la nación" ( $n^{\text {o }} 35$ ). Otras enmiendas planteadas por diputados de AP procuran evitar no sólo el término "divorcio" en el texto constitucional, sino cualquier otro que pueda entenderse implícitamente como sinónimo de divorcio, como ocurría con la palabra “disolución” (nº 3, n 72).

La Ponencia aceptó la enmienda planteada por el GP de UCD ( $\left.n^{\circ} 779\right)$ para redactar el apartado primero del art. 27, acogiendo también las tesis planteadas no sólo por alguno de sus diputados ( $n^{\circ}$ 736) sino también por un diputado de AP ( $\left.n^{\circ} 35\right)$, rechazándose todas las enmiendas de carácter progresista a las que nos referíamos anteriormente. Similar suerte corren la totalidad de las presentadas al apartado segundo, pues la Ponencia mantiene inalterada la redacción original (Congreso de los Diputados, 1978a: 1538-1539).

Así, con nueva numeración (art. 31), el texto fijado para el debate en la Comisión difiere del que había redactado originalmente la Ponencia únicamente en una alteración del texto del primer apartado en el sentido de que sea el matrimonio el único cauce para el establecimiento de la familia. El debate en la Comisión del actual artículo 32 tuvo lugar en su sesión de 23 de mayo (Congreso de los Diputados, 1978f), centrándose el mismo en la cuestión del divorcio únicamente, al contrario de lo que sucedería en el Senado, como veremos más adelante, en el que la cuestión de la igualdad entre la mujer y el hombre en el matrimonio centralizó el debate gracias a la intervención de la Senadora Belén Landáburu.

De todas las enmiendas planteadas en la fase inicial del debate en la Comisión, se mantiene la $\mathrm{n}^{\circ} 3$ de Pedro de Mendizábal Uriarte (AP), a fin de "suavizar" el texto en aras del consenso y evitar expresiones que pudieran provocar rechazo en los sectores más

\footnotetext{
${ }^{10}$ La patria potestad la ostentaba el padre, situación que se mantuvo inalterada hasta la aprobación de la Ley de 13 de mayo de 1981.
} 
conservadores defensores de la indisolubilidad del matrimonio. En similares términos defiende también su enmienda $\mathrm{n}^{\mathrm{o}} 72$ de texto alternativo al apartado segundo, Gregorio López-Bravo (AP), que aboga por la supresión de las referencias al régimen del matrimonio en el plano constitucional, solicitando la eliminación del término "disolución". Mucho más beligerante contra el divorcio, la enmienda $n^{\circ} 35$, de Licinio de la Fuente (AP), por la que se añade un punto tercero que establece como requisito para el reconocimiento y regulación del divorcio "el referéndum público de la Nación" (Congreso de los Diputados, 1978f: 2619-2620). Estas enmiendas, todas de diputados de AP, pusieron en evidencia la falta de consenso en dicho grupo parlamentario, pues, como recuerda el portavoz, en este caso, de la Ponencia, Miquel Roca, fue el mismo Manuel Fraga el que con su voto contribuyó a la mayoría que aprobó el texto de la ponencia. Todas ellas fueron rechazadas, aunque es significativo que concitaran idéntica proporción de votos en contra que de abstenciones, pues pone de manifiesto la diversidad de concepciones opuestas acerca del matrimonio y, por conexión, de la familia.

A pesar de que los votos particulares y enmiendas de carácter progresista planteados por los representantes de los Grupos Socialista, Minoría Catalana y Comunista se mantuvieron, en principio, para defenderlos en el debate en Comisión, finalmente fueron retirados y se presentó una propuesta de redacción conjunta por seis grupos parlamentarios, entre los que se contaban los representados en la Ponencia, que presentan una enmienda in voce. Defendió la enmienda en nombre de la Ponencia Miquel Roca, en cuya intervención destacó la ambigüedad en la redacción del precepto a favor de un texto de consenso ${ }^{11}$, que obtuvo 31 votos favorables de la Comisión (Congreso de los Diputados, 1978f: 2622).

A pesar de su rechazo en el debate en Comisión, las enmiendas más conservadoras y reaccionarias anteriormente reseñadas fueron mantenidas por el GP de AP para su defensa en el Pleno, en un intento de zafarse del compromiso alcanzado por Manuel Fraga en el seno de la Ponencia. También mantuvo su enmienda $n^{\circ} 607$ el GP Vasco, que proponía el texto ya reproducido aquí en el análisis de la primera fase del debate en el Congreso del artículo relativo al matrimonio.

En el Pleno del Congreso, en la exposición sobre el conjunto del proyecto que tuvo lugar en la sesión de 4 de julio, antes de iniciarse el debate al articulado, el representante del GP de AP, Manuel Fraga, hizo referencia al matrimonio y a la familia "estable" como "la condición básica de una concepción moral de la sociedad", en consonancia con las posiciones defendidas por este grupo parlamentario desde el inicio del debate (Congreso de los Diputados, 1978g: 3777).

Pero debemos acudir al debate en Pleno para comprobar que, en comparación con otras materias relevantes para la consecución de la igualdad de mujeres y hombres, la relativa al

\footnotetext{
${ }^{11}$ El texto de consenso, numerado como artículo 30 en el texto del proyecto de Constitución aprobado por el Pleno del Congreso de los Diputados el 24 de julio de 1978, era el siguiente: "1. A partir de la edad núbil, el hombre y la mujer, en plena igualdad de derechos y deberes, podrán contraer matrimonio. 2. La ley regulará las formas del matrimonio, los derechos y deberes de los cónyuges, las causas de separación y disolución y sus efectos" (Congreso de los Diputados, 1978j: 2950).
} 
matrimonio sí fue objeto de discusión, reflejo del debate recogido en los medios de comunicación (prensa, especialmente) acerca de la división social existente sobre la legalización del divorcio. A las reivindicaciones de la inclusión del divorcio en el texto constitucional por parte de los movimientos de mujeres y feministas y de un amplio espectro social de izquierdas, se contraponía la Iglesia y buena parte de la sociedad más conservadora o temerosa de un giro social de tal radicalidad que hiciera desaparecer por completo las estructuras sociales existentes.

En el debate de este artículo en el Pleno del Congreso (Congreso de los Diputados, 1978i: 4073-4087) sólo dos enmiendas planteadas por diputados de AP tendentes a suavizar o a suprimir los términos o expresiones que pudieran interpretarse como una aceptación del divorcio en la Constitución fueron sometidas a discusión y votación, aunque finalmente se impuso el texto aprobado en Comisión, con los votos en contra de AP al apartado segundo del artículo. Para la explicación de voto únicamente intervinieron los Fraga Iribarne (AP), Herrero de Miñón (UCD) y Solé Tura (GP Comunista). En su intervención, este último destacó que todas las enmiendas tendentes a la constitucionalización del divorcio sin ambigüedades fueron retiradas para propiciar el consenso y encontrar un punto de equilibrio entre todas las fuerzas políticas representadas en el Congreso. Esto fue confirmado por el representante de UCD, que ratificó los términos ambiguos en que fue redactado este precepto al exponer la posición de su grupo parlamentario, claramente contraria a la directa constitucionalización del divorcio y a favor de su regulación por ley ordinaria ${ }^{12}$.

En aras de ese consenso, por tanto, se pospuso una de las principales reivindicaciones feministas.

\section{c) Familia: artículo 39}

Los votos particulares y enmiendas presentadas al art. 34 (el actual 39) del texto originario del Anteproyecto de Constitución elaborado por la Ponencia ${ }^{13}$ ofrecen un panorama bastante completo sobre las dos grandes posiciones diferentes acerca de la concepción de la familia y los aspectos relativos a la misma que debían incluirse en la Constitución. De un lado, las más progresistas, las más avanzadas, que, recogiendo las reivindicaciones de los movimientos de mujeres y feministas, pretendían la inclusión en este precepto de programas de planificación familiar, incluyendo la interrupción voluntaria del embarazo. De otro, las que, considerando a la familia una institución natural básica

\footnotetext{
${ }^{12}$ La aprobación de la ley del divorcio, en consonancia con esta posición, tuvo lugar en 1981, con el último gobierno de UCD.

${ }^{13}$ El texto era el siguiente: “1.Los poderes públicos aseguran la protección económica, jurídica y social de la familia, en particular, por medio de prestaciones sociales, de disposiciones fiscales y de cualquier otra medida adecuada. 2. La madre y los hijos, iguales éstos ante la ley con independencia de su filiación, disfrutarán de la protección oficial del Estado y de todos los poderes públicos. 3. Los padres tienen para con los hijos habidos fuera del matrimonio los mismos deberes que respecto de los nacidos en él, sin perjuicio del respeto a la institución familiar" (Congreso de los Diputados, 1978: 675).
} 
previa a cualquier organización estatal, rechazaban los postulados anteriores, centrando sus pretensiones de reforma en la protección a los menores, como los miembros más vulnerables en el ámbito familiar.

Alineados con la primera de las posiciones expuestas, estaban los votos particulares formulados por el GP Socialista y el GP Comunista y, de forma más moderada, el GP de la Minoría Catalana, junto a algunas enmiendas, bien de adhesión a alguno de los votos formulados (enmienda $\mathrm{n}^{\mathrm{o}}$ 64, del diputado de Euzkadiko Ezquerra al voto del GP Socialista, o la $n^{\circ} 487$, del GP Mixto), bien mejorando la redacción del precepto de los mismos (enmienda $n^{\circ}$ 699, de la diputada comunista $\mathbf{M}^{\text {a }}$ Dolores Calvet).

En congruencia con la formulación de su voto al artículo 27 , que ya contemplaba la protección de la familia en la regulación del derecho a contraer matrimonio, el GP Socialista formuló un voto particular de supresión a este artículo 34. Por su parte, el GP Comunista, coincidiendo con el voto particular de la Minoría Catalana y apoyado por enmiendas presentadas por otros grupos parlamentarios ( $n^{\circ} 137$, de Minoría Catalana; $n^{\circ}$ 611, del GP Vasco), propuso una nueva redacción del apartado 3 a fin de eliminar la expresión "sin perjuicio del respeto a la institución familiar", dado que ello podría llegar a alterar gravemente el reconocimiento que en el propio precepto se hacía en orden a la total igualdad de los deberes que los padres guardan con los hijos, independientemente de su filiación matrimonial. Además de este cambio, el GP Comunista también propone en su voto añadir un nuevo apartado 4 en el que se elevase a rango constitucional la planificación familiar a cargo de la Seguridad Social, incluyendo en la misma la interrupción del embarazo, como medida para ejercer una maternidad y una paternidad responsables (Congreso de los Diputados, 1978: 705).

Con una nueva redacción, que aligeraba el texto hasta reducirlo a sólo dos apartados sin omitir ninguna de las propuestas contenidas en este voto particular, la diputada comunista $M^{a}$ Dolores Calvet, propone la siguiente enmienda ( $\left.{ }^{\circ} 699\right)$, que reproducimos por su interés:

"1. Los Poderes Públicos aseguran la protección económica, jurídica y social de la maternidad y de la familia, por medio de prestaciones sociales, de disposiciones fiscales y de programas de planificación familiar a cargo de la Seguridad Social y de cualquier otra medida adecuada. Entre los métodos de dicha planificación podrá incluirse la interrupción del embarazo, en las condiciones fijadas por la ley.

2. Los hijos son iguales ante la ley, con independencia de su filiación. Los padres tienen para con los hijos habidos fuera del matrimonio los mismos deberes que respecto de los nacidos en él" (Cortes Generales, 1980: 433).

Frente a estas posiciones progresistas y coincidentes con las reivindicaciones feministas, el resto de las enmiendas presentadas se incardinan en la segunda concepción de la familia a que aludíamos al comienzo de este apartado: la exclusiva protección de los derechos de los niños como finalidad principal de la familia, institución natural y básica preexistente al Estado. Así, la mayoría de las enmiendas presentadas en este sentido 
proponen la inclusión de un nuevo apartado en o una nueva redacción de los ya existentes que haga especial referencia a los derechos del niño reconocidos por la normativa internacional $\left(n^{\circ} 5, n^{\circ} 22, n^{\circ} 45, n^{\circ} 138, n^{\circ} 162, n^{\circ} 739\right)$. Fue esta segunda postura la que se alzó con el triunfo en el nuevo informe de la Ponencia que se sometería a debate en la Comisión al conseguir añadir un nuevo apartado a este artículo ${ }^{14}$.

En el debate en Comisión se alcanzó un texto "de consenso" que rechazó todos los planteamientos progresistas que encarnaban las aspiraciones del movimiento de mujeres y feministas, siendo así, una vez más, la moneda de cambio que facilitó el acuerdo. El nuevo texto de consenso (casi idéntico al que finalmente figura en nuestra Constitución en el art. 39), dejando inalterada la esencia del artículo, ofrecía simplemente una redacción mejorada respecto de las anteriores y pasó a incorporarse al Dictamen de la Comisión, por tanto, sin mayor debate, con la aprobación de 30 votos favorables, sin votos en contra ni abstenciones (Congreso de los Diputados, 1978f: 2624).

En aras, pues, del consenso, se abandonaron las pretensiones de constitucionalizar la planificación familiar y la interrupción del embarazo, pues la retirada de los votos particulares implicaron la renuncia a defenderlas en el debate posterior en el Pleno del Congreso. Esto puede interpretarse como máximo desinterés por introducir constitucionalmente derechos que afectaban y afectan de modo especial a las mujeres, aunque las razones aducidas se referían a la extemporaneidad de las pretensiones, como manifestó el representante del GP Comunista, Solé Tura, con ocasión del debate sobre el artículo del derecho a la vida (Congreso de los Diputados, 1978h: 3963-3964). Cabe destacar también en este sentido, la ya conocida intervención de Peces-Barba en la explicación de voto al artículo 14 (actual 15) del GP Socialista sobre la intención de dificultar una futura regulación permisiva del aborto por parte de los conservadores de AP al sustituir el término "persona" por el de "todos" en referencia a la titularidad del derecho a la vida (Congreso de los Diputados, 1978h: 3966-3967).

En definitiva, que el consenso, aplazando el debate "sine die", de un lado, y, de otro, la rigidez de las reglas que regían el debate en el Pleno, que permitían la discusión de grupos de artículos, la cuestión de la familia no fue debatida. En efecto, por lo que al artículo 35 (hoy art. 39) se refiere, debido a los criterios formales del debate, fue votado conjuntamente con los artículos 34 y 36, que no guardaban ninguna relación con el mismo, pues se refería el primero a la libertad en la economía de mercado y el segundo a la política económica, el pleno empleo y las condiciones laborales, cuestiones que concitaron la atención de las escasas intervenciones, con el total olvido del artículo referido a la familia, que fue aprobado en los mismos términos planteados en el Dictamen de la Comisión la sesión plenaria del Congreso de 11 de julio de 1978 (Congreso de los Diputados, 1978i: 4114-4115).

\footnotetext{
${ }^{14} \mathrm{El}$ texto del nuevo apartado 4 añadido por la Ponencia fue el siguiente: "Los poderes públicos aseguran especialmente el cumplimiento de la declaración de los derechos del niño proclamada por la Asamblea de las Naciones Unidas el 20 de noviembre de 1959” (Congreso de los Diputados, 1978a: 1623).
} 


\section{La igualdad de género en el debate de la Constitución en el Senado}

El Proyecto de Constitución aprobado por el Congreso de los Diputados el 21 de julio de 1978 fue remitido al Senado, habilitándose hasta el 7 de agosto el plazo para la presentación de enmiendas. Su número fue elevadísimo lo que, junto al escaso plazo de tiempo concedido para su examen y discusión, imposibilitó que la Ponencia pudiera redactar su informe. Por ello, el debate en la Comisión de Constitución del Senado tuvo que hacerse artículo por artículo, con turnos de intervención escasísimos. El debate en el Pleno del Senado concluye el 5 de octubre de 1978, apenas dos meses después de que la Cámara Alta hubiese recibido el texto del proyecto de Constitución remitido por el Congreso. Esta celeridad permite adivinar ya que los temas más relevantes para las mujeres que en este trabajo se abordan no fueran objeto del debate que hubieran merecido, con la salvedad del relativo al matrimonio, como más adelante se señalará.

Aunque en la Comisión de Constitución no había ninguna senadora, la dinámica de los trabajos permitió la intervención tanto en el seno de la Comisión como en el posterior debate en el Pleno, de aquéllas que habían presentado enmiendas. En este sentido, debemos destacar las intervenciones de la senadora por designación real, Belén Landáburu, especialmente respecto del artículo sobre el matrimonio.

\subsection{Las cuestiones más relevantes en relación a la posición de las mujeres}

\section{a) Igualdad: artículos 9.2 y 14}

Como fiel reflejo de lo sucedido en el Congreso, parece que el valor igualdad reflejado en el artículo 1.1 del Proyecto no suscitó ninguna controversia. No así el artículo 9.2, referido a la igualdad real y el art. 13 (hoy 14), la igualdad formal, a los que se presentaron cuatro y siete enmiendas, respectivamente.

Por lo que se refiere a las cuatro enmiendas $\left(n^{\circ} 12,591,824\right.$ y 825) presentadas al apartado 2 del artículo 9, la polémica en la Comisión Constitucional del Senado (Senado, 1978: 1729-1733) se centró en la supresión de la referencia a los grupos y la sustitución del término "individuo" por el de "persona" ( $\mathrm{n}^{\mathrm{o}}$ 12, presentada por el GP Progresistas y Socialistas Independientes y la $\mathrm{n}^{\mathrm{o}} 825$, presentada por Luis Miguel Enciso, de UCD) por entender que la libertad e igualdad a título individual no podían equipararse a la libertad e igualdad de los grupos.

También en el sentido de cambio de unos términos por otros se orientaba la enmienda $n^{\circ}$ 591, presentada por Carlos Ollero, de la Agrupación Independiente, que proponía cambios en la redacción de los verbos que implicaban la acción de los poderes públicos de forma que denotasen un mayor compromiso de éstos.

Pero quizá lo más interesante fue la propuesta realizada en el debate en Comisión, en la defensa de la enmienda $\mathrm{n}^{\mathrm{o}} 12$, que proponía la supresión de la referencia a "los grupos" y la 
sustitución del término "individuo" por el de "persona"15. Villar Arregui, representante del GP PSI, presenta una enmienda in voce para ubicar el art. 9.2 como un apartado en el art. 13 (hoy 14) que recogía el principio de igualdad ante la ley, por entender que "se trata de un precepto que desborda los límites de la democracia formal para, con su dinamismo, permitir penetrar en los ámbitos o en las áreas de la democracia real o, si se prefiere, de la democracia integral" (Senado, 1978: 1730). La enmienda, incluida la formulada in voce, fue aceptada, en principio, en su integridad, por UCD. Sin embargo, esta última enmienda de cambio de ubicación fue inmediatamente retirada por el propio PSI por existir discrepancias internas en cuanto al traslado del texto (Senado, 1978: 1732). Se perdió de esta forma una gran oportunidad para constitucionalizar como principio y derecho (exigible, por tanto, ante la jurisdicción) la denominada "igualdad real o material", que ha posibilitado en nuestro ordenamiento, no sin dificultades, la adopción de medidas de acción positiva tendentes a corregir la situación de desigualdad existente entre mujeres y hombres ${ }^{16}$.

Finalmente, frente al dictamen de la Comisión aceptando el sentido de la enmienda propuesta por PSI de supresión de la referencia a "los grupos" y sustitución del término "individuo", por "persona", el GP Socialista, que proponía el mantenimiento del mismo texto remitido originalmente por el Congreso, presenta un voto particular en este sentido ( $\mathrm{n}^{\circ} 56$ bis), que, con el apoyo explícito de UCD, es finalmente aprobado como texto definitivo por el Senado (Senado, 1978c: 2948-2952 y Senado, 1978e: 3456). De no haber prosperado este texto, hubiera resultado jurídicamente imposible la aprobación de normativa tendente a la eliminación de la denominada discriminación estructural, pues se hubiera reafirmado la concepción individualista del Derecho, dominante hoy todavía (Barrère, 2001).

Por lo que se refiere al artículo 13 (actual 14) se presentaron siete enmiendas ( ${ }^{\circ} 8,141$, 258, 323, 661, 662 y 1095) cuyo contenido variaba apostando, en unos casos, por la supresión de la enumeración de las causas de no discriminación, y, en otros, por la inclusión en esa enumeración de otras circunstancias, como la lengua o la posición económica. Todas fueron o bien retiradas o bien rechazadas sin debatirlas, aprobándose casi unánimemente la formulada in voce por el senador Camilo J. Cela que perfeccionaba la redacción del precepto al introducir el término "condición", junto al de "circunstancia"17 (Senado, 1978a: 1799). Fue este texto el aprobado finalmente por el Pleno del Senado sin debate alguno por no haberse formulado ningún voto particular al mismo (Senado, 1978c: 2962).

\footnotetext{
${ }^{15}$ El texto de la enmienda al art. 9.2 era el siguiente: "Corresponde a los poderes públicos promover las condiciones para que la libertad y la igualdad de las personas sean reales y efectivas, suprimir los obstáculos que impidan o dificulten su plenitud, y facilitar la participación de todos los ciudadanos en la vida política, económica, cultural y social." (Cortes Generales, 1980a: 2674).

${ }^{16}$ Buen ejemplo de ello es la Ley Orgánica 3/2007, de 22 de marzo, para la igualdad efectiva de mujeres y Hombres.

${ }^{17}$ El texto del art. 14 fue la redacción definitiva que se incorporó a la Constitución: "Los españoles son iguales ante la ley, sin que pueda prevalecer discriminación alguna por razón de nacimiento, raza, sexo, religión, opinión o cualquier otra condición o circunstancia personal o social”.
} 


\section{b) Matrimonio: artículo 32}

A pesar de las restricciones temporales a las que se ha hecho referencia, el debate sobre el matrimonio fue uno de los más intensos de los desarrollados en el Senado (Sevilla et al., 2006: 160 y Senado, 1978b: 2000-2015). Al artículo 30 del proyecto remitido por el Congreso (actual 32), se presentaron un total de 13 enmiendas, cuatro de ellas a la totalidad del texto, tres al apartado 1 y seis al apartado $2^{18}$.

Por lo que se refiere a las enmiendas a la totalidad, también aquí, como en el Congreso, se planteaban dos posiciones opuestas y que relacionaban matrimonio y familia. Las más avanzadas, que pretendían el reconocimiento de otro tipo de uniones distintas al matrimonio e incluían cuestiones como la de la planificación familiar y la referencia directa al divorcio; y las más conservadoras, que se inclinaban por la consagración de la familia basada en el matrimonio como institución natural y básica de la sociedad y se oponían a la disolución del vínculo matrimonial.

Como representativa de la primera postura podríamos citar la enmienda presentada por Lluís Ma Xirinacs, del GP Mixto, que contemplaba tanto las relaciones sexuales y afectivas entre las personas como el matrimonio u otra clase de relaciones estables de familia, estableciendo que en cualquier caso dichas relaciones habrían de basarse en la igualdad de los consortes entre sí y de ambos respecto de los hijos comunes. Asimismo pretendía la constitucionalización de la libertad de decidir el número de hijos que se desean tener y, en consecuencia, el derecho a acceder a la información necesaria y a los medios que permitiesen su ejercicio. Por último, se refería directamente a la ley del divorcio como medio de disolución del matrimonio (Cortes Generales, 1980a: 2860).

En la postura contraria podríamos citar, por todas, la enmienda presentada por Marcial Gamboa, del GP Mixto, que proponía reducir a un solo apartado la redacción del artículo 30, remitiendo a la ley la regulación del régimen del matrimonio y suprimiendo la referencia a su disolución por entender que ésta planteaba para gran parte de la sociedad española un "grave problema de conciencia por sus convicciones religiosas y morales" (Cortes Generales, 1980a: 2731).

Pero, al margen de las dos posturas extremas sobre la totalidad del precepto, lo que llama la atención del debate de este artículo es que, a diferencia de lo que sucedió en el Congreso, donde la polémica se centró, sobre todo y de forma casi exclusiva, en la cuestión del divorcio, en el debate en la Comisión de Constitución del Senado la discusión central del apartado 1 fue la igualdad entre mujeres y hombres.

Y ello a pesar de que inicialmente parecía que lo único que iba a suscitar más polémica respecto del apartado 1 era la determinación de la edad de los cónyuges debido a la desafortunada redacción del texto del Congreso, fruto de la copia literal del art. 16 de la Declaración Universal de

\footnotetext{
${ }^{18} \mathrm{El}$ art. 30 estaba redactado en los siguientes términos: "1. A partir de la edad núbil, el hombre y la mujer, en plena igualdad de derechos y deberes, podrán contraer matrimonio. 2. La ley regulará las formas del matrimonio, los derechos y deberes de los cónyuges, las causas de separación y disolución y sus efectos" (Congreso de los Diputados, 1978j: 2950).
} 
Derechos Humanos de 1948. En este sentido se plantearon tres enmiendas ( $n^{\circ} 155,713$ y 855). La presentada por Camilo José Cela, de la Agrupación Independiente, proponía fijar la edad para contraer matrimonio en el texto del artículo, por suponer la expresión "edad núbil" una tautología (Cortes Generales, 1980a: 2724). Recibió el apoyo inmediato de UCD en el debate en Comisión, retirando la suya. La presentada por Félix Calvo, del GP de UCD, también iba encaminada a precisar la edad válida para contraer matrimonio, haciendo referencia a la edad púber-núbil como aquella en la que ya pueden el hombre y la mujer contraer matrimonio, si bien los menores de 19 años necesitarían del consentimiento de los padres. Llama la atención la justificación de esta enmienda al señalar que "la pubertad es cuando se convierte una niña en mujer, tanto somática como psíquicamente, por lo que entraña el despertar de la femineidad. Una muchacha es núbil cuando se hace fértil" (Cortes Generales, 1978a: 2950). Una vez más, se pone en evidencia la ideología sobre la principal misión de las mujeres, la de ser madres, pues lo determinante en este caso para contraer matrimonio es la capacidad para la reproducción.

Pero, como advertíamos más arriba, en el transcurso del debate de este apartado en la Comisión la senadora Belén Landáburu (GP Mixto) imprime al mismo un giro de 180 grados al proponer una enmienda in voce al apartado 1, a fin de trasladar al mismo el contenido de la presentada por ella ( $n^{\circ} 427$ ) al apartado 2 del artículo. La enmienda citada proponía que al texto del apartado 2 se añadiese el siguiente: "Igualmente desarrollará el principio de igualdad jurídica de ambos cónyuges" (Cortes Generales, 1980a: 2845). Razones de congruencia jurídica fueron las esgrimidas por la senadora para fundamentar su enmienda in voce. La primera, trasladar a este artículo el principio de igualdad y no discriminación ya aprobado en el que entonces era el artículo 13 (hoy art. 14) del texto del proyecto constitucional. La segunda, el hecho de que en el mismo texto se hubiese reflejado este principio en el acceso a las funciones y cargos públicos, suponía una aplicación del mismo al ámbito del Derecho público, por lo que lo lógico era trasladar también el principio de igualdad y no discriminación al ámbito del Derecho privado, es decir, a la regulación del matrimonio y la familia.

Para la senadora Landáburu, no incluir en la Constitución la referencia a la igualdad en la esfera privada, en la que se desarrollan las más íntimas relaciones entre mujeres y hombres, supondría un retroceso, especialmente teniendo en cuenta las modificaciones que ya se habían introducido en la legislación ordinaria por la Ley 14/1975, de 2 de mayo (Moraga García, 2008: 235-240) y las que se estaban llevando a cabo en esa misma legislatura, dentro de los trabajos ordinarios de las Cámaras y en la Comisión General de Codificación, de la que ella misma formaba parte desde diciembre de 1972 y en la que se creó una sección especial para el estudio de la reforma de la situación jurídica de las mujeres (Ruiz Franco, 2006: 173).

Con el giro introducido por la senadora Landáburu en su discurso, todos los enmendantes aprovechan no tanto para discutir o debatir como para pronunciarse a favor de la igualdad entre mujeres y hombres. Pero es nuevamente la senadora la que reconduce las intervenciones para situar debidamente la intención de su enmienda: asegurar constitucionalmente la igualdad jurídica de los cónyuges no tanto ni sólo antes del matrimonio, sino después de éste, dado que es precisamente el cambio de estado civil el que acentúa las desigualdades y la discriminación por 
razón de sexo (Senado, 1978b: 2006-2007). En el texto consensuado y aprobado por la Comisión y el Pleno no se aprecia, sin embargo, este rico matiz ${ }^{19}$, lo que obligaría en años posteriores a alcanzar este objetivo mediante la reforma de la legislación ordinaria (Vallés Amores, 2006: 125129).

El debate del apartado 2, al igual que había sucedido en el Congreso, giró en torno a tres posiciones: la de rechazo del divorcio, la de constitucionalización del mismo y la vía intermedia, esto es, remitir a la ley las causas y efectos de su disolución, donde se evitaba el polémico término “divorcio". Fue esta última la posición que se adoptó, es decir, no plasmarlo en la Constitución pero dejar abierta la posibilidad a una futura ley del divorcio que habría de esperar tiempos más sosegados para desarrollarse. Posponer esta cuestión crucial para la igualdad de género y presente en todas las reivindicaciones feministas, fue, por tanto, uno de los pilares sobre los que se edificó el consenso constitucional ${ }^{20}$.

\section{c) Familia: artículo 39}

Al igual que ocurrió en el debate sobre el matrimonio, tanto las enmiendas como los votos particulares que se mantuvieron al texto de este artículo 35 (el actual 39) ${ }^{21}$ también reproducían, las tres posturas que ya se habían manifestado en el debate previo en el Congreso en torno a la concepción de la familia.

Así, de un lado, las más progresistas, como consecuencia del principio de igualdad y no discriminación por razón de sexo, planteaban la inclusión en este artículo de reivindicaciones feministas como la investigación de la paternidad, la patria potestad compartida o la planificación familiar que, incluyendo la protección del embarazo, garantizase el ejercicio de una maternidad y una paternidad responsables. De otro lado, en la postura más conservadora, se insistía en la inclusión del reconocimiento de la familia como la institución natural básica preexistente a la organización estatal, en los términos establecidos tanto en el art. 16 de la Declaración Universal de Derechos Humanos de 1948, como en el Pacto Internacional de Derechos Civiles y Políticos. No faltaron posiciones intermedias que propugnaban que en el precepto debía, en todo caso, garantizarse de forma más explícita y completa, la protección de los menores como los miembros más vulnerables de la familia. Pero lo cierto es que la primera de las posiciones, atendiendo tanto al número de enmiendas que fueron presentadas como a la minoritaria y de heterogénea composición de los GP que la mantenían, estaba en franca desventaja respecto de la postura contraria, de signo marcadamente conservador.

\footnotetext{
${ }^{19}$ El texto era el siguiente: "El hombre y la mujer, a partir de la edad fijada por la ley, tienen derecho a contraer matrimonio basado en la igualdad jurídica de los cónyuges" (Senado, 1978f: 3562).

${ }^{20}$ Como es sabido, la primera ley del divorcio se aprobó, tras mucha polémica, en la legislatura siguiente. El debate constitucional sobre la misma se puede consultar en Sevilla, Julia (2010).

${ }^{21}$ Véase el texto del art. 35 en el apartado referido a la familia en el debate en el Congreso en este mismo trabajo.
} 
Respecto de las enmiendas más progresistas, sólo cuatro de las diecisiete enmiendas planteadas ( $n^{\circ} 27,244,471$ y 705$)$ eran susceptibles de ser enmarcadas en la primera de las posiciones descritas, es decir, en la postura progresista que aglutinaba las reivindicaciones feministas.

La enmienda $\mathrm{n}^{\circ} 27$, presentada por el PSI, proponía una nueva redacción a los apartados 2, 3 y 4. Por lo que se refiere al apartado 2, se añadía que la ley posibilitará la investigación de la paternidad, como corolario de la no discriminación por razón de sexo, previsión que ya fue incluída en el art. 43 de la Constitución de 1931. En el apartado 3 se proponía una nueva redacción más corta para explicitar los deberes de los padres respecto de sus hijos, pero la novedad más importante era la inclusión de la garantía por ley de la patria potestad compartida de forma efectiva por el padre y por la madre, también como corolario de la constitucionalización del principio de igualdad y no discriminación por razón de sexo. Por último, en el apartado 4, se proponía la supresión al reenvío a Tratados internacionales, estableciéndose un genérico mandato a los poderes públicos y a la sociedad para la protección especial de los niños (Cortes Generales, 1980a: 2681-2682). En la idéntica línea, fundamentada asimismo en el principio de igualdad y no discriminación por razón de sexo, la enmienda $n^{\circ} 244$, presentada por Mateo Antonio García-Mateo, también del PSI, proponía la reforma al apartado 2 para añadir la investigación de la paternidad y un nuevo apartado que recogiese el ejercicio compartido en condiciones de igualdad de la patria potestad (Cortes Generales, 1980a: 2771).

Algo más allá que éstas iba la enmienda $n^{\circ} 471$, presentada por el jesuita Lluis $\mathbf{M}^{\mathrm{a}}$ Xirinacs, del GP Mixto. No sólo contemplaba los extremos anteriores sino que además proponía que los poderes públicos asegurasen con carácter subsidiario a los padres la protección integral a los hijos e incluía una mención a la adopción a fin de asegurar en la tramitación de la misma la intervención y vigilancia del Estado. También planteaba la promoción por los poderes públicos de programas de planificación familiar, incluida la interrupción del embarazo, a fin de dar contenido al ejercicio de una maternidad y una paternidad responsable (Cortes Generales, 1980a: 2862-2863).

Finalmente, la enmienda $n^{\circ} 705$, presentada por Alfonso Moreno, del PSI, coincidía, en cierta medida, con la anterior enmienda de Xirinacs en el sentido de constitucionalizar la interrupción del embarazo, pero lo hacía no tanto como corolario de la igualdad y no discriminación por razón de sexo, sino como garantía de la libertad de conciencia y, principalmente, a fin de procurar la igualdad desde una perspectiva socioeconómica. En esta enmienda se proponía la adición de un nuevo apartado dirigido a constitucionalizar que por ley se regulasen las condiciones en que se llevase a cabo la interrupción del embarazo ${ }^{22}$.

Mucho más numerosas fueron las enmiendas encuadrables en la posición conservadora. Así, de las siete enmiendas planteadas ( $n^{\circ} 121,178,197,406,428,715$ y una

\footnotetext{
${ }^{22}$ Concretamente, el texto propuesto era el siguiente: "Una ley establecerá que las prácticas dirigidas a la interrupción anticipada de la gestación tengan lugar con las garantías sanitarias precisas" (Cortes Generales, 1980a: 2950).
} 
enmienda in voce), cuatro lo fueron por senadores del Grupo Mixto, entre ellas una planteada por la Senadora Belén Landáburu (enmienda $\mathrm{n}^{\circ}$ 428). Al margen de esta nota que da una idea de la sólo en apariencia atomización de las posiciones, lo cierto es que, en definitiva, todas estas enmiendas proponían redacciones en parecidos términos encaminadas a que se incluyese en el texto del artículo la referencia a la familia como elemento natural y fundamental de la sociedad, constitucionalizando de esta manera la misma fórmula utilizada por el artículo 16 de la Declaración Universal de los Derechos Humanos y el Pacto Internacional de Derechos civiles y Políticos.

Junto a ambas posiciones, las restantes enmiendas tenían por objeto enfatizar la especial protección que debía dispensársele a los menores (enmiendas no 235, 254 y 269) o a otras personas en especial situación de vulnerabilidad como, en palabras del Senador Cela, "los subnormales" (enmienda ${ }^{\circ} 159$ ). De difícil encaje, aunque más próxima a la postura conservadora fue la enmienda $\mathrm{n}^{\circ}$ 232, presentada por Fidel Carazo, del Grupo Mixto, que pretendía graduar la protección otorgada por el Estado a la familia en función del número de sus miembros. Finalmente otras enmiendas, como la planteada in voce por el GP Socialista, simplemente pretendían que el texto del artículo volviese a la redacción originaria, tal y como había sido aprobado por el Congreso.

Como resultado del debate en la Comisión no se recogió ninguna de las dos posturas enfrentadas, aceptándose sólo aquellas enmiendas que se referían a la especial protección de los menores y de las personas vulnerables.

Por tanto, de las diecisiete enmiendas planteadas a este artículo, casi la totalidad fueron rechazadas, manteniéndose para su defensa en el Pleno sólo ocho de ellas que, en forma de votos particulares, recogían tanto las aspiraciones más progresistas como las más conservadoras. Sin embargo, no todos llegaron a discutirse en el Pleno, retirándose un buen número de ellos en aras del consenso, tal y como había sucedido en el Congreso.

En el caso de los votos particulares más conservadores, fueron retirados por entender que la postura que defendían podía subsumirse en otros preceptos anteriormente debatidos y aprobados definitivamente por el Pleno ${ }^{23}$. Por el contrario, otros fueron retirados bien en aras del consenso o por entender que de ninguna manera iban a obtener la aprobación de la Cámara. Fue el caso de la renuncia de los Senadores Xirinacs y Moreno a sus votos particulares referidos a la constitucionalización del aborto o el de la retirada del voto particular formulado por PSI, que proponía la inclusión de la garantía por ley de la patria potestad compartida de forma efectiva en condiciones de igualdad por el padre y la madre.

Sólo se sometió al debate en el Pleno y fue aprobado por amplia mayoría el voto particular $n^{\circ} 201$, que recogía parcialmente la enmienda $n^{\circ} 27$ del Grupo PSI, a fin de incluir la posibilidad de investigación de la paternidad. En su defensa intervino el Senador Villar Arregui, que, aludiendo las recientes modificaciones del Código Penal respecto de los delitos de adulterio y amancebamiento, intenta ganarse el voto de las posiciones conservadoras pues

${ }^{23}$ Concretamente el art. 10.2, referente a la Declaración Universal de los Derechos Humanos como criterio de interpretación de todos los derechos y libertades constitucionalmente reconocidos. 
arguye que ello posibilitaría despejar las dudas que sobre su paternidad pudieran albergar los hombres casados respecto de sus esposas. También centra su intervención apelando a la plena eficacia de la previsión constitucional sobre los iguales deberes que madres y padres tienen respecto de los hijos que no operaría en los casos de madres solteras, sobre las que recaería injustamente la exclusiva responsabilidad de los hijos, de negarse la posibilidad de investigación de la paternidad, produciéndose así una discriminación constitucional en contra de la mujer, pues "estadísticamente es muy superior el número de casos de madres solteras que el número de hijos habidos por mujeres casadas de hombres distintos de su marido" (Senado, 1978d: 3075-3076).

\section{Conclusión}

Como se desprende del análisis del íter parlamentario de las tres cuestiones más relevantes para la modificación de la situación de las mujeres en aras de la igualdad de género, el ya mítico y mitificado consenso constitucional se edificó, en buena medida, sobre la preterición de las mismas.

Ello tuvo como resultado la indefinición constitucional en muchos de estos aspectos, tales como el divorcio o el aborto, cuyo reconocimiento posterior por ley se reveló, como se sabe, especialmente conflictivo y complejo. Todo ello supuso una ralentización del avance de las mujeres en la consecución de mayores cotas de igualdad y que subsiste todavía hoy, 35 años después de que se iniciara la elaboración de nuestra Norma Fundamental.

Ni la anecdótica participación femenina fue un tema que saliese a relucir en los debates parlamentarios ni las cuestiones más relevantes para las mujeres ocuparon un lugar destacado en los mismos.

\section{BIBLIOGRAFÍA}

- Barrère, Ma Ángeles (2001): Problemas del Derecho antidiscriminatorio: subordinación versus discriminación y acción positiva versus igualdad de oportunidades". En Revista Vasca de Administración Publica, nº 60, pp. 145-166.

- Congreso de los Diputados (1977): Diario de sesiones, $\mathrm{n}^{\circ} 5$, de 27 de julio.

- Congreso de los Diputados (1978): Boletín Oficial de las Cortes, $\mathrm{n}^{\circ}$ 44, de 5 de enero.

- Congreso de los Diputados (1978a): Boletín Oficial de las Cortes, $\mathrm{n}^{\circ}$ 82, de 17 de abril.

- Congreso de los Diputados (1978b): Diario de Sesiones, no 59, de 5 de mayo.

- Congreso de los Diputados (1978c): Diario de Sesiones, nº 60, de 8 de mayo. 
- Congreso de los Diputados (1978d): Diario de Sesiones, n ${ }^{\circ}$ 67, de 16 de mayo.

- Congreso de los Diputados (1978e): Diario de Sesiones, no 69, de 18 de mayo.

- Congreso de los Diputados (1978f): Diario de Sesiones, ${ }^{\circ}$ 72, de 23 de mayo.

- Congreso de los Diputados (1978g): Diario de Sesiones, no 103, de 4 de julio.

- Congreso de los Diputados (1978h): Diario de Sesiones, no 105, de 6 de julio.

- Congreso de los Diputados (1978i): Diario de Sesiones, no 107, de 11 de julio.

- Congreso de los Diputados (1978j): Boletín Oficial de las Cortes, $\mathrm{n}^{\mathbf{0}}$ 135, de 24 de julio.

- Cortes Generales (1980): "Congreso de los Diputados. Enmiendas presentadas al Anteproyecto". En Constitución Española. Trabajos parlamentarios. Vol I. Madrid: Publicaciones de las Cortes Generales, pp. 65-500.

- Cortes Generales (1980a): "Senado. Enmiendas al texto del Proyecto de Constitución aprobado por el Pleno del Congreso de los Diputados". En Constitución Española. Trabajos parlamentarios. Vol III. Madrid: Publicaciones de las Cortes Generales, pp. 2613-2952.

- Moraga García, Ma Ángeles (2008): "Notas sobre la situación jurídica de la mujer en el Franquismo". En Feminismo/s, no. 12, pp. 229-252.

- Radcliff, Pamela (2012): "El debate sobre el género en la Constitución de 1978: orígenes y consecuencias del nuevo consenso sobre la igualdad". En Ayer, nº 88, pp. 195225.

- Ruiz Franco, Rosario (2006): "María Telo y la participación de mujeres juristas en la Comisión General de Codificación (1973-1975). En Asparkía, nº 17, pp. 165-180.

- Senado (1978): Diario de Sesiones, $\mathrm{n}^{\circ}$ 42, de 23 de agosto.

- Senado (1978a): Diario de Sesiones, $\mathrm{n}^{\circ} 43$, de 24 de agosto.

- Senado (1978b): Diario de Sesiones, $\mathrm{n}^{\circ}$ 45, de 29 de agosto.

- Senado (1978c): Diario de Sesiones, no 59, de 26 de septiembre.

- Senado (1978d): Diario de Sesiones, ${ }^{\circ}$ 61, de 28 de septiembre.

- Senado (1978e): Boletín Oficial de las Cortes, $n^{\circ}$ 157, de 6 de octubre.

- Senado (1978f): Boletín Oficial de las Cortes, n 161 , de 13 de octubre.

- Sevilla, Julia, et al. (2006) (dir. y coord.): Las mujeres parlamentarias en la legislatura constituyente. Madrid: Cortes Generales-Ministerio de la Presidencia.

- Sevilla, Julia (2010) (dir. y coord.): Las parlamentarias en la I legislatura: Cortes Generales (1979-1982). Madrid: Congreso de los Diputados-Senado.

- Vallés Amores, M $M^{a}$ Luisa (2006): “La posición jurídica de la mujer a través de las reformas del Derecho de Familia". En Feminismo/s, nº. 8, pp. 115-129. 